\section{Providing Experiential Business and Management Training for Biomedical Research Trainees}

\author{
Kimberly A. Petrie, ${ }^{\dagger}$ Robert H. Carnahan, ${ }^{+}$Abigail M. Brown, ${ }^{\dagger}$ and \\ Kathleen L. Gould ${ }^{\text {t\$* }}$ \\ †Office of Biomedical Research Education and Training, " Department of Cancer Biology, and \\ §Department of Cell and Developmental Biology, Vanderbilt University School of Medicine, \\ Nashville, TN 37232
}

\begin{abstract}
Many biomedical PhD trainees lack exposure to business principles, which limits their competitiveness and effectiveness in academic and industry careers. To fill this training gap, we developed Business and Management Principles for Scientists, a semester-long program that combined didactic exposure to business fundamentals with practical team-based projects aimed at solving real business problems encountered by institutional sharedresource core facilities. The program also included a retreat featuring presentations by and networking with local life science entrepreneurs and final team presentations to expert judges. Quantitative and qualitative metrics were used to evaluate the program's impact on trainees. A pretest-posttest approach was used to assess trainees' baseline knowledge and mastery of module concepts, and each individual's pretest and posttest responses were compared. The mean score improved by more than 17 percentage points. Trainees also took an online survey to provide feedback about the module. Nearly all participants agreed or strongly agreed that the module was a valuable use of their time and will help guide their career decisions and that project work helped drive home module concepts. More than $75 \%$ of trainees reported discussing the module with their research advisors, and all of these participants reported supportive or neutral responses. Collectively, the trainee feedback about the module, improvement in test scores, and trainee perception of advisor support suggest that this short module is an effective method of providing scientists with efficient and meaningful exposure to business concepts.
\end{abstract}

\section{INTRODUCTION}

Thirty years ago, one in three biomedical $\mathrm{PhD}$ graduates in the United States could expect to become tenure-track faculty; today, only one in six can expect to do so (Stephan, 2012; Garrison, 2017). The range of careers pursued by $85 \%$ of today's $\mathrm{PhD}$ graduates is varied and includes research and research-related careers in academia, government, industry, and the nonprofit sector (Freedman, 2009; National Institutes of Health [NIH], 2012; Janssen and Sever, 2014; Sinche, 2016). By and large, biomedical training programs have not kept pace with preparing $\mathrm{PhD}$ students and postdoctoral fellows for the varied careers they pursue (NIH, 2012; Mathur et al., 2015; Meyers et al., 2015; Fuhrmann, 2016; Denecke et al., 2017). Notably, there is a paucity of programs that provide trainees with exposure to and experience in business principles and standards (Mason et al., 2016). Without meaningful experiential exposure to business practices, trainees interested in business-related careers cannot make wellinformed decisions regarding this career trajectory and they are not as well prepared to take on industry jobs (Fiske, 2016; Mason et al., 2016). Also, as countless principal investigators (PIs) have speculated to us, such a lack of knowledge and experience among trainees who become faculty or lab directors in academia, government, or research institutes may be leading to inefficiencies that reduce cost-effectiveness of
Kenneth Gibbs, Monitoring Editor Submitted May 4, 2017; Revised June 19, 2017; Accepted June 21, 2017

CBE Life Sci Educ September 1, 2017 16:ar51 DOI:10.1187/cbe.17-05-0074

*Address correspondence to: Kathleen L. Gould (kathy.gould@avanderbilt.edu).

() 2017 K. A. Petrie et al. CBE-Life Sciences Education (๑) 2017 The American Society for Cell Biology. This article is distributed by The American Society for Cell Biology under license from the author(s). It is available to the public under an Attribution-Noncommercial-Share Alike 3.0 Unported Creative Commons License (http:// creativecommons.org/licenses/by-nc-sa/3.0). "ASCB®" and "The American Society for Cell Biology ${ }^{\circledR}$ " are registered trademarks of The American Society for Cell Biology. 
laboratories and institutional resources and limit the commercialization of inventions.

To address this gap in trainee preparedness, we developed a new program for biomedical $\mathrm{PhD}$ students and postdoctoral fellows (collectively called trainees) that combined didactic exposure to business principles with practical team-based research aimed at solving real business problems encountered by some of our institutional shared-resource core facilities. These facilities, of which there are more than 30 at Vanderbilt University, offer a wide array of cutting-edge biomedical technologies, high-end instrumentation, and technical support and training. They run as semi-independent nonprofit entities responsible for recovering some or all of their operating expenses, and facility directors are staff or faculty who all have some level of responsibility for short- and long-term budgeting, service/product development, human resources management, marketing, and operational management. In some cases, institutional facility directors have had some business training, but in other cases, the lack of business acumen is an acknowledged challenge to the efficient performance of such facilities (Turpen et al., 2016).

We describe here our approach for this program, which has been implemented two times, and report on the outcomes in terms of trainees' understanding of fundamental business and management concepts and opinions as to how participation impacted career interest and preparedness. Research advisor support for complementary but nondisciplinary training is widely perceived to be a barrier to implementing career and professional development programs like this one (Sauermann and Roach, 2012; Meyers et al., 2015; Fuhrmann, 2016; Denecke et al., 2017), so we also assessed trainees' perceptions of how their research advisors viewed their participation in the program. We anticipate that this new program, which appears successful in meeting its educational goals, will be scalable to other cohorts of science, technology, engineering, and mathematics (STEM) $\mathrm{PhD}$ trainees on our campus and transportable to other institutions wishing to provide similar opportunities for their trainees. We anticipate that program participation will ease our trainees' transitions to business-related careers in science or prepare them to run their own laboratories or companies. Further, the program has spurred assessment of business practices and innovations within the core facilities to improve service capacity.

\section{METHODS \\ Program Funding}

The program was funded by a 2015 Career Guidance for Trainees award from the Burroughs Wellcome Fund. Program expenses included the cost of the module instructor, effort for the module director, speaker and participant costs for the module retreat, and small prizes for the top two teams at the final project competition.

\section{Program Frequency}

This article includes data from the pilot program, which ran from January to April 2016 and again from January to April 2017 with distinct cohorts of participants.

\section{Program Leadership}

The program was collaboratively developed, taught, and evaluated by faculty from the School of Medicine and the College of Arts and Sciences. Overall program development, participant selection, and evaluation was overseen by the associate dean for Biomedical Sciences in conjunction with her team in the Office of Career Development in the School of Medicine. The module was co-led by the director of a Vanderbilt institutional core facility who attended all classes to help facilitate discussion, co-organized the retreat, recruited core managers to participate, and worked with the instructor and core directors to select suitable problems to serve as projects. The module was taught by an associate professor of the Practice in Managerial Studies who adapted the content from an undergraduate course. In addition to teaching didactic lectures and case studies, he met with core directors to help define and refine business problems and coached trainee teams in their project work.

Six core facility managers participated in the program in each of its two implementations, with four managers involved both times. They were invited to participate because they had previously expressed interest in obtaining additional business training to enhance the operation of their cores. In addition, they each had one or more suitable business problems that could be refined as trainee projects, and they were able to commit to consulting with project teams and attending most classes. Most core facility managers attended class meetings regularly and contributed relevant examples to classroom discussions of business concepts.

\section{Participant Recruitment and Selection}

Vanderbilt University School of Medicine has more than 1100 $\mathrm{PhD}$ trainees in the biomedical sciences, a group comprising more than 700 graduate students and more than 400 postdoctoral fellows. To solicit applications for the program, we posted a description of the program on our website and blog and advertised the program via a bimonthly e-newsletter and through direct email-marketing campaigns to the graduate student and postdoctoral fellow listservs. Interested trainees were asked to submit an application that included a brief personal statement explaining their interest in the program and how it related to their career goals. In addition, applicants were asked to submit a CV highlighting research and academic accomplishments and relevant extracurricular activities or leadership experience. Only graduate students who had passed their qualifying examination and were in good academic standing were eligible to apply.

Sixty-four trainees applied for the program in 2016, and 36 trainees applied for the program in 2017 . We speculate that the drop in applications was due to the fact that there is a relatively low turnover of trainees from year to year, and those who took the module in 2016 were removed from the applicant pool in 2017.

Applicants were evaluated for 1 ) evidence of significant interest, for instance, previous participation in related activities offered by our office; 2) clarity in describing how the program fits with their career goals; 3) evidence of research productivity consistent with career stage (i.e., scholarly presentations and publications); and 4) leadership in extracurricular activities. Although no specific level of scientific productivity or extracurricular involvement was required, we viewed productivity in research and extracurricular engagement as evidence of effectiveness in time management. After an initial review of applicants based on these criteria, we selected a cross-section of trainees with various career goals: trainees interested in industry or academic research and trainees interested in research-related careers that clearly benefit from a solid foundation in business 
TABLE 1. Profile of module participants

\begin{tabular}{lll}
\hline & $\mathbf{2 0 1 6}(\boldsymbol{n}=\mathbf{2 4})$ & $\mathbf{2 0 1 7}(\boldsymbol{n}=\mathbf{2 0})$ \\
\hline $\begin{array}{l}\text { Training status } \\
\quad \text { Graduate student (GS) }\end{array}$ & $62.5 \%(15)$ & $45 \%(9)$ \\
$\quad$ Postdoctoral fellow (PD) & $37.5 \%(9)$ & $55 \%(11)$ \\
Year in training & & \\
$\quad$ First year & $4 \mathrm{PD}$ & $6 \mathrm{PD}$ \\
$\quad$ Second year & $2 \mathrm{PD}$ & $1 \mathrm{PD}$ \\
Third year & $2 \mathrm{PD}, 1 \mathrm{GS}$ & $3 \mathrm{PD}, 4 \mathrm{GS}$ \\
Fourth year & $0 \mathrm{PD}, 8 \mathrm{GS}$ & $1 \mathrm{PD}, 4 \mathrm{GS}$ \\
Fifth year & $1 \mathrm{PD}, 6 \mathrm{GS}$ & $0 \mathrm{PD}, 1 \mathrm{GS}$ \\
Gender & & \\
$\quad$ Female & $62.5 \%(15)$ & $35.0 \%(7)$ \\
$\quad$ Male & $37.5 \%(9)$ & $65.0 \%(13)$ \\
Previous experience & & \\
$\quad$ Business course & $29.2 \%(7)$ & $30 \%(6)$ \\
Business plan competition & $4.2 \%(3)$ & $15 \%(3)$ \\
\hline
\end{tabular}

principles, such as entrepreneurship and drug/device approval and production. Preference was also given to trainees who would be able to attend all class meetings and to postdoctoral fellows who had been in their laboratory for at least 6 months before the application date. In the end, 24 trainees were chosen to participate in 2016 and 20 were chosen to participate in 2017 (Table 1). Among the selected applicants, 11 of the 44 selected participants in the two cohorts reported that they had participated in prior business courses or business-plan competitions.

Applicants signed a statement committing to attend all class sessions unless they had an academic conflict such as a professional conference or presentation. Trainees were not required to obtain permission from their research advisors to participate in the program, but they were strongly encouraged to discuss the time commitment with their advisors before accepting a position in the module.

\section{Program Components}

The program structure was identical in 2016 and 2017. It was 12 weeks long and consisted of a non-credit bearing short course (called a "module" to be consistent with terminology used for other professional development opportunities sponsored by our office), a half-day retreat featuring talks by scientific business leaders, a team project, and a final presentation by project teams. Although the module was non-credit bearing, trainees received a certificate of completion from our office. This strategy allows for postdoctoral fellows (who are not enrolled students at the university) and post-qualifying exam stage graduate students (who have completed all their didactic credits) to take the module free of charge. Module participants met with the instructor for 2 hours each week, and one to two short articles were assigned as readings. During the last 4 weeks of the module, most teams met several times outside class to complete their projects and develop their final presentations.

\section{Didactic Components}

Given the limited time frame of the module, an emphasis was placed on providing a basic introduction to business and management principles. As shown in Table 2, the first 7 weeks
TABLE 2. Module syllabus and instructional approach

\begin{tabular}{|c|c|}
\hline $\begin{array}{l}\text { Topics (each topic was } 1 \text { week, except } \\
\text { where noted) }\end{array}$ & Specific activities \\
\hline $\begin{array}{l}\text { Finance: accounting, financial reporting, } \\
\text { managerial finance, budgeting, cash } \\
\text { management }\end{array}$ & $\begin{array}{l}\text { Precourse evaluation } \\
\text { Lecture } \\
\text { Discussion }\end{array}$ \\
\hline $\begin{array}{l}\text { Human resources/people: organizational } \\
\text { design, recruiting, hiring, training, } \\
\text { leadership, development, motivation, } \\
\text { compensation ( } 2 \text { weeks in 2017) }\end{array}$ & $\begin{array}{l}\text { Lecture } \\
\text { Discussion }\end{array}$ \\
\hline $\begin{array}{l}\text { Marketing: promotion, advertising, social } \\
\text { media, public relations, product } \\
\text { development, product management, } \\
\text { customer management ( } 2 \text { weeks in } \\
\text { 2016) }\end{array}$ & $\begin{array}{l}\text { Lecture } \\
\text { Discussion }\end{array}$ \\
\hline $\begin{array}{l}\text { Technology: information technology, } \\
\text { technology infrastructure, data } \\
\text { management }\end{array}$ & $\begin{array}{l}\text { Lecture } \\
\text { Discussion }\end{array}$ \\
\hline $\begin{array}{l}\text { Operations: facilities and operations } \\
\text { management, quality, efficiency, } \\
\text { continuous improvement }\end{array}$ & $\begin{array}{l}\text { Lecture } \\
\text { Discussion }\end{array}$ \\
\hline Retreat & $\begin{array}{l}3-4 \text { invited speakers } \\
\text { Roundtable discussions }\end{array}$ \\
\hline $\begin{array}{l}\text { Problem solving } \\
\text { Project workshop }\end{array}$ & $\begin{array}{l}\text { Minilecture } \\
\text { Project teamwork }\end{array}$ \\
\hline $\begin{array}{l}\text { Project management } \\
\text { Project workshop }\end{array}$ & $\begin{array}{l}\text { Minilecture } \\
\text { Project teamwork }\end{array}$ \\
\hline $\begin{array}{l}\text { Data-driven decision making } \\
\text { Project workshop }\end{array}$ & $\begin{array}{l}\text { Minilecture } \\
\text { Project teamwork }\end{array}$ \\
\hline $\begin{array}{l}\text { Final project workshop } \\
\text { Final presentations }\end{array}$ & $\begin{array}{l}\text { Postcourse evaluation } \\
\text { Project teamwork } \\
\text { Final presentations }\end{array}$ \\
\hline
\end{tabular}

consisted of facilitated discussions, lectures, and case-based learning exercises. A point of emphasis was that many management and operational changes faced by businesses are, at their core, similar across different types of organizations, so application of effective management and business principles can positively impact all types of organizations. Significant effort was made to present examples from a range of organization types and then contextualize the content into situations familiar and relevant to our biomedical trainees (e.g., lab management and operations, biotechnology innovation). Core facility managers contributed to weekly discussions by describing how the business and management principles presented play out in their laboratories.

The syllabus was nearly identical in 2016 and 2017, with one small change. In 2016, the trainees were highly engaged in a classroom discussion of human resources topics. Thus, in 2017, the instructor devoted two class meetings to human resources instead of one. To compensate, the number of class meetings devoted to marketing was reduced to one.

\section{Schedule}

The module was designed to be minimally disruptive to trainee schedules by requiring a sustained time commitment over the duration of the program (12 weeks) but a limited time commitment on a weekly basis (2-6 hours). The class met in the morning from 8:00 to $10: 00 \mathrm{am}$, which allowed 
trainees to complete a full day of uninterrupted research and thus maintain productivity in their laboratories and research projects. Care was also taken to avoid scheduling program events during national and religious holidays, local school district breaks, and major scientific society meetings.

\section{Retreat}

At the conclusion of the didactic phase, trainees were invited to a half-day, on-campus retreat focusing on the intersection of business and science. A key component of our program is to provide trainees opportunities to learn through engagement with business leaders and innovators, so four scientists who held various roles in different industries were invited to give brief talks, participate in panel discussions, and lead interactive breakout sessions with trainees. The 2016 speakers included the founder and chief executive officer (CEO) of a laboratory services company, the vice president of bioinformatics for a healthcare information technology company, a venture capitalist, and the director of an academic research institute, and the 2017 speakers included the founders and CEOs or chief scientific officer (CSO) of medical diagnostic companies. All shared their experiences transitioning from bench scientist to a leadership role, and each described the management and business skills that are vital to a successful scientific company or research group. The last session of the retreat was also the launching point of the team-project phase, with all teams conducting their first in-depth team meetings.

\section{Team-Project Component}

The last 4 weeks of the module, participants worked in teams of three or four to develop a solution to a business problem encountered by an institutional core research facility. The class continued to meet weekly during the project phase with the major portion of each class set aside for team-project work. Several of these meetings incorporated short minilectures focused on practical tools and strategies for problem solving, project management, and data-driven decision making that teams incorporated into their projects.

Before the start of the module, program leaders conducted a series of meetings with the core directors to define projects that were nonoverlapping, had the potential for tangible impact in the host facility, were aligned with the major topic areas covered (Table 2), and were of appropriate complexity for the trainee teams.

\section{Final Presentations}

The module concluded with each team giving a 7-minute presentation of its project and proposed recommendations. Project topics and descriptions for the 2016 and 2017 cohorts are included in the Supplemental Material.

A panel of judges with expertise in core management, laboratory management, and/or business management was assembled to provide feedback on team presentations. Judges rated the teams from 1 (poor) to 5 (exceptional) for the following five measures relating to the quality and feasibility of the recommended solution and the quality of the presentation:

1. Clear statement and description of the problem

2. Clear description of the approach and process, including team strategy, methods used, alternatives investigated/ discarded, and why
3. Collection, evaluation, and use of data to drive the decisionmaking process

4. Utility of the recommended solution(s): Does the solution address the problem? Is the solution feasible?

5. Overall presentation quality

\section{Module Assessment}

Vanderbilt Institutional Review Board approval was obtained to assess the impact of the module using quantitative and qualitative metrics (IRB 151913). The evaluation instrument was nearly identical in 2016 and 2017, except where noted in the following paragraph. All statistical analyses were conducted using GraphPad Prism 7 and GraphPad Instat 3 software.

A pretest-posttest design was used to assess the trainees' baseline knowledge and mastery of module concepts. Questions for a 45-item multiple-choice test were written by the course instructor and aligned with the course learning objectives and syllabus. The test was administered online in class via SurveyMonkey on the first and last days of the module. Each trainee received a unique link to take the test so that individual responses on the pretest and posttest could be matched. Participants were given 25 minutes to take the exam. Most questions on the multiple-choice exam were the same in 2016 and 2017, except for two questions that were rewritten for clarity and four questions that were replaced to reflect small changes in the 2017 syllabus. In both 2016 and 2017, all participants completed the pretest; 22 of 24 participants completed the posttest in 2016, and 19 of 20 participants completed the posttest in 2017. In a given year, the pre- and posttest items were identical, so each individual's initial and final responses were compared using a two-tailed paired $t$ test to assess whether their knowledge of business concepts changed between the pre- and posttest. Only participants who completed both the pre- and posttest were included in the statistical analysis of test scores.

A qualitative survey was administered at the same time as the multiple-choice test. Both the pre- and postmodule surveys gauged trainees' perceptions of research advisor awareness and support for their participation in the module, trainees' comfort level with six topic areas covered by the module, and trainees' career plans. On the postmodule survey, trainees were also asked 10 scaled items and open-ended questions about their overall impressions, module time commitment, module content, and their communication with their research advisors about the module. The qualitative survey questions are included in the Supplemental Material.

Trainees used a Likert scale to report their comfort level with six business and management concept areas covered by the module. For analysis, Likert-scale responses were converted to numerical ratings ( 4 = very comfortable, $3=$ moderately comfortable, 2 = slightly comfortable, 1 = not comfortable), and a two-tailed Wilcoxon matched-pairs test was used to detect changes in individuals' comfort levels with each concept area between the pretest and posttest. Only participants who completed both the pre- and posttest surveys were included in the statistical analysis of comfort levels.

Trainees used a Likert scale (will definitely pursue, strongly considering, moderately considering, slightly/not at all considering, not enough information to decide) to rank their level of interest in 21 different career categories; the career categories are the same ones adopted by the National Institutes of Health 

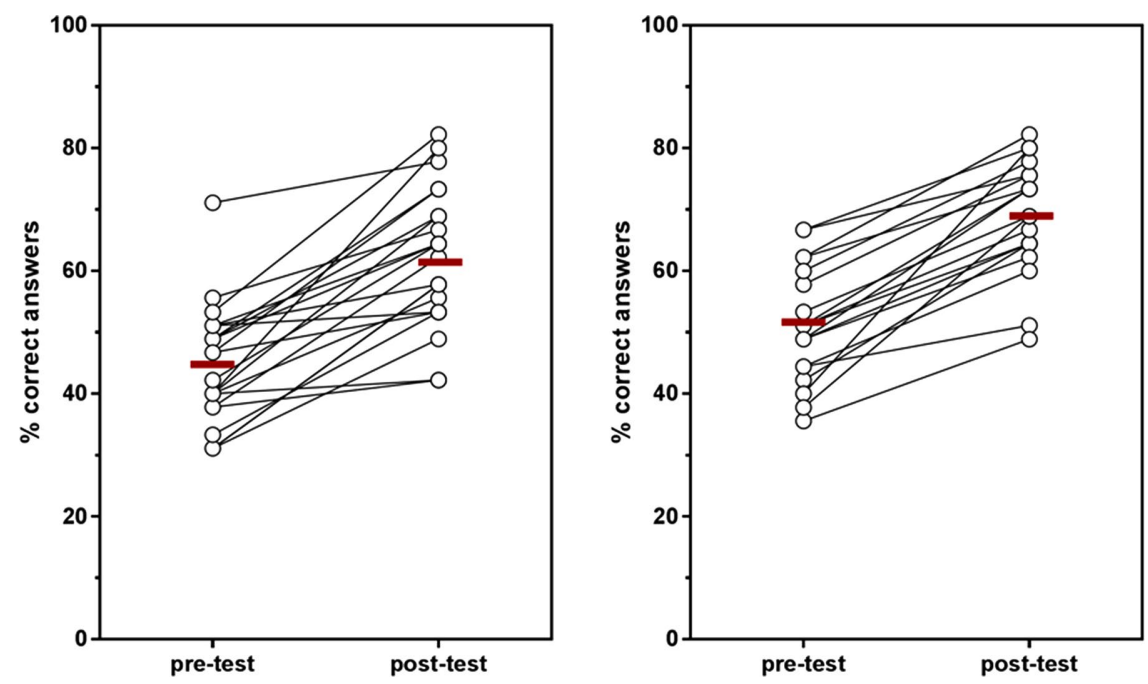

FIGURE 1. Performance of individual trainees on the pre- and posttest knowledge exam in (left) $2016(n=22)$ and (right) $2017(n=19)$. Open circles represent percent correct for each individual, and lines between columns represent matched pre- and posttest scores for each individual. Red horizontal lines represent the mean percent correct for all trainees. No significant differences were observed between graduate students and postdoctoral fellows at pretest or posttest in 2016 or 2017 (2016 pretest: GS M $=44.5$ and $\mathrm{SD}=10.8, \mathrm{PD} M=44.4$ and $\mathrm{SD}=7.5, t(20)=0.008412, p=0.9934 ; 2016$ posttest: $\mathrm{GS} M=$ 59.3 and $S D=10.7, P D M=68.3$ and $S D=10.5, t(20)=1.852, p=0.0789 ; 2017$ pretest: GS $M=49.4$ and $S D=8.7, P D M=52.5$ and $S D=10.1, t(17)=0.7154, p=0.4841 ; 2017$ posttest: $G S M=70.5$ and $S D=10.2, P D M=67.8$ and $S D=9.0, t(17)=0.6069, p=0.5520$ ).
No significant differences were observed. Likewise, there was no significant difference in the performance of GS compared with PD on the posttest assessment in either cohort. Because the two groups did not differ with regard to their performance on the quantitative assessments, the GS and PD pretest scores and GS and PD posttest scores for each year were combined for all subsequent analyses. However, because the 2017 cohort pretest scores were significantly higher than the 2016 cohort's pretest scores $(t(39)=2.261$; $p=0.0294$ ), the quantitative assessments from the 2016 and 2017 cohorts were analyzed separately (Figure 1).

In 2016, the mean score for all individuals on the posttest $(62.2 \pm 11.2 \%)$ was significantly higher than the mean pretest scores $(44.5 \pm 9.6 \% ; p<0.0001, t(21)=$ 8.054), showing an average improvement of 17.7 points or $\sim 18 \%$. In 2017 , the mean score for all individuals on the posttest $(69.0 \pm 9.3 \%)$ was significantly higher than the mean pretest scores $(51.2$ \pm 9.4\%; $p<0.0001, t(18)=9.909)$, showing a similar improvement of 17.8 points $(\sim 18 \%)$.
BEST consortium for our consortium-wide program evaluation and similar to those used in the MyIDP tool from ScienceCareers (Fuhrmann et al., 2012; Meyers et al., 2015). Participants received the list of categories by email 2 days before taking the survey, so they had time to become familiar with the definitions. For assessment of changes in participant career interests, Likert-scale responses were collapsed into dichotomous categories (considering or not considering) and a McNemar's test was used to detect changes in career interest between the first and last day of class. Three Likert-scale categories were collapsed into "considering" (will definitely pursue, strongly considering, moderately considering) and two Likert-scale categories were collapsed into "not considering" (slightly/not at all considering and not enough information to decide). Only participants who completed both the pre- and posttest surveys were included in the statistical analysis of career interests.

\section{RESULTS}

\section{Quantitative Assessment of Module Concepts}

To determine whether an individual trainee's understanding of module concepts changed between the beginning and end of the course, trainees took an online pretest and posttest on the first and last days of class, respectively. The pre- and posttest questions were identical and aligned with the module learning objectives. An individual trainee's pre- and posttest responses were matched through the use of personalized links to the online test.

To address the possibility that graduate students (GS) and postdoctoral fellows (PD) performed differently on the quantitative assessments of module concepts, we used a two-tailed $t$ test to compare the pretest scores of GS and PD in each year's cohort.

\section{Qualitative Assessment of Module Concepts}

At pretest, most of the 2016 cohort reported being "not comfortable" or "slightly comfortable" with each of the six concept areas, with mean comfort levels ranging from $1.32 \pm$ 0.48 to $1.77 \pm 0.69$. Individuals reported significantly higher levels of comfort with all six concept areas at the time the posttest was administered, with mean comfort levels ranging from $2.77 \pm 0.53$ to $3.32 \pm 0.48$ (Figure 2 ). The 2017 cohort showed a similar significant increase in comfort level in all six concept areas from pretest to posttest (Supplemental Material).

\section{Impact of the Module on Trainee Career Decision Making and Trajectory}

On the first day of class in 2016, all but one module participant reported considering a career in industry research, and more than $60 \%$ of participants reported they were considering a career as a PI in a research-intensive institution or in "business of science" or in "drug/device approval and production" (Figure $3 \mathrm{~A})$. On the last day of class, interest in careers in industry research and "drug/device approval and production" and as PIs were unchanged, but participants reported significantly greater interest in careers relating to "support of science-related products" ( $p<0.05)$. There was also a noticeable but not significant increase in the number of trainees considering careers relating to business of science ( $p=0.07)$.

The 2017 cohort expressed interest in a broader range of career paths than the 2016 cohort (Figure 3B). On the first day of class, nearly all 2017 participants reported they were considering a research career in industry and a career relating to the business of science; $79 \%$ were also considering careers as 


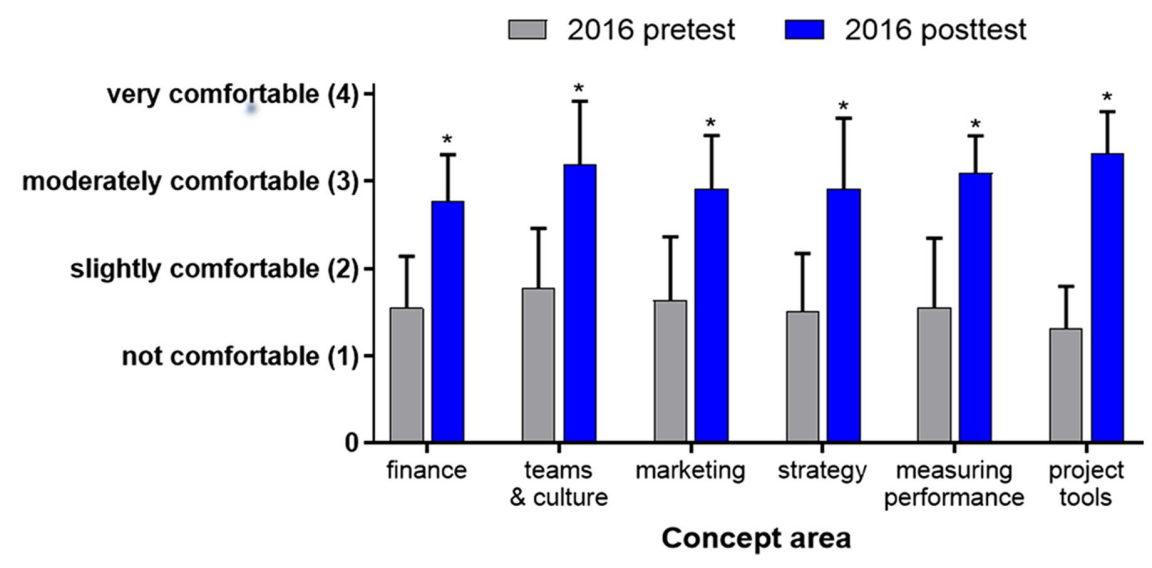

FIGURE 2. Comfort with course concepts. Participants in 2016 indicated their comfort level with six different course concept areas using a Likert scale. Text comfort levels were converted to numerical rankings (very comfortable $=4$, moderately comfortable $=3$, slightly comfortable $=2$, not comfortable $=1$ ). Bars represent mean comfort level $\pm S D$ in each concept area at pretest (gray bar) and posttest (blue bar). For each concept area, a Wilcoxon matched-pairs test was used to detect differences in comfort levels between individuals' pretest and posttest scores. ${ }^{*}, p<0.0001$ compared with pretest. $n=22$.

module was a valuable use of their time, and more than $90 \%$ strongly agreed or agreed that working on a project helped drive home the concepts taught in class.

In an optional free-text open-ended question, participants were asked whether there were any topics that should be covered in more detail. Of the 41 survey respondents, 19 answered this question, and the most frequently cited topics were finance and accounting (five respondents) and project management tools and strategies (five respondents). In another optional open-ended question, participants were asked to identify the most useful aspect of the module. Of the 41 survey respondents, 39 answered this question, and nine respondents mentioned two or three aspects they found useful. Eleven respondents said that the most useful aspect of the module was the overall introduction to business concepts. Thirty-nine respondents cited a specific structural element of the class as most useful, including the

a PI or in drug/device approval and production, research administration, clinical research management, or science policy. On the last day of class, interest in research in industry and business of science was nearly identical. Interest in all other career paths fell slightly, but none of the changes were statistically significant.

At the time this article was written, 42 of the 44 module participants were still in training; two module participants from the 2016 cohort had accepted permanent jobs in the private biotechnology sector. Although the career outcomes of all module participants will not be known for several years, $95 \%$ of the participants in both cohorts agreed or strongly agreed that the module provided them with knowledge that will help guide their career decision making, and $90 \%$ of the participants in both cohorts agreed or strongly agreed that the module helped to solidify their career interests (Figure 4).

\section{Time Spent on Module-Related Activities and Advisor Support for Module Participation}

During the didactic portion of the class, none of the participants in the 2016 or 2017 cohort reported spending more than 1-2 hours per week outside class on module-related readings and preparation. During the project portion of the module, participants spent more time on module-related work, but not more than 3-4 hours per week (Figure 5).

Nearly $75 \%$ of survey respondents in both the 2016 and 2017 cohorts reported discussing the module with their research advisors, and all of these reported their advisors were supportive or neutral about their participation (Figure 6).

\section{Trainee Impressions}

Participants were asked a series of scaled questions about their impressions of the module. Because the 2016 and 2017 modules were nearly identical in terms of structure and content, qualitative feedback was combined for analysis. One hundred percent of participants strongly agreed or agreed that the didactic lectures (11), the project (11), classroom discussions of personal experiences or case studies (nine), the retreat (four), or the mini-workshops covering practical project management or problem-solving tools (four).

\section{Project Outcomes}

For the final presentations, scores for 2016 teams ranged from 17.8 to 22.2 with a mean score of 20.6 out of 25 possible points. Scores for 2017 teams ranged from 16.7 to 22.6 with a mean score of 19.6 out of 25 possible points.

After the module ended in 2016, the core directors met several times to discuss the tools and recommendations produced by the trainee teams, and in a few cases, the trainees continued their involvement through to implementation. Immediate impacts for the institution have already been realized, such as the submission of a large instrumentation grant for recommended automation in a biobanking core and the launching of a 3D-printing service tailored to biomedical labs. Longer-term implementations of trainee team products are also underway, including deploying a novel real-time lab metrics dashboard tool and finalizing a best practices guide for core marketing.

\section{DISCUSSION}

To our knowledge, this is one of the first programs for biomedical $\mathrm{PhD}$ students and postdoctoral fellows that provides exposure to fundamental business and management principles applicable to a range of careers inside and outside academia and the first such program to collaborate with research core facilities to offer trainees practical project opportunities. A recent survey conducted by the Council of Graduate Schools (CGS) suggests that business-related courses for scientists are relatively rare (Denecke et al., 2017), and where they do exist, they usually focus specifically on either laboratory management strategies applicable to PIs running independent research programs or on technology commercialization strategies for faculty and trainees interested in commercializing their research 


\section{A. 2016 cohort}

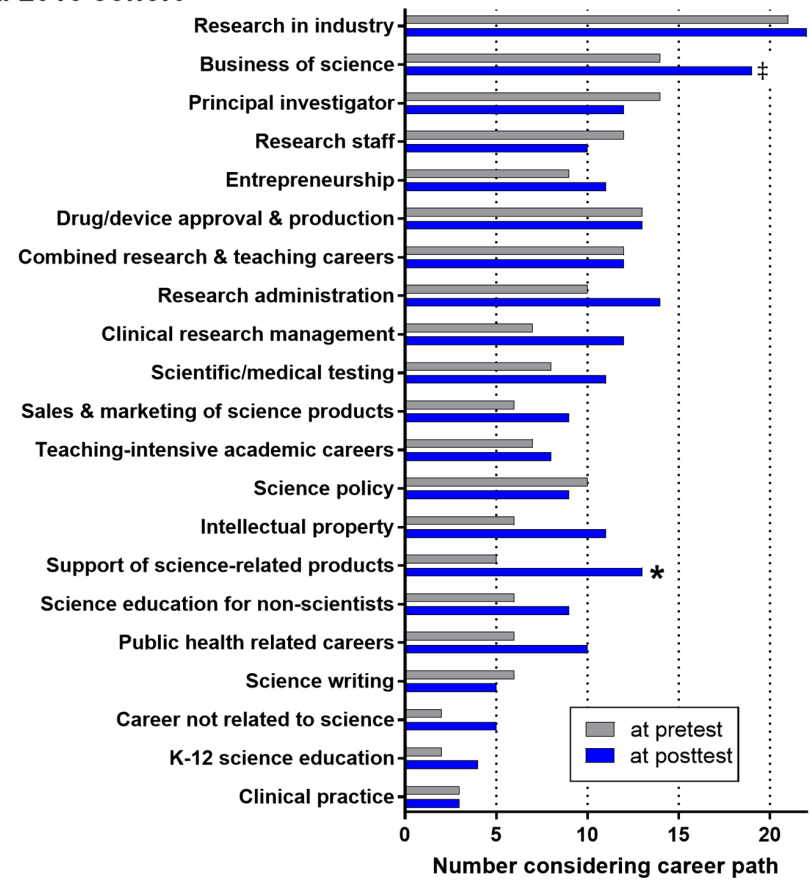

B. 2017 cohort

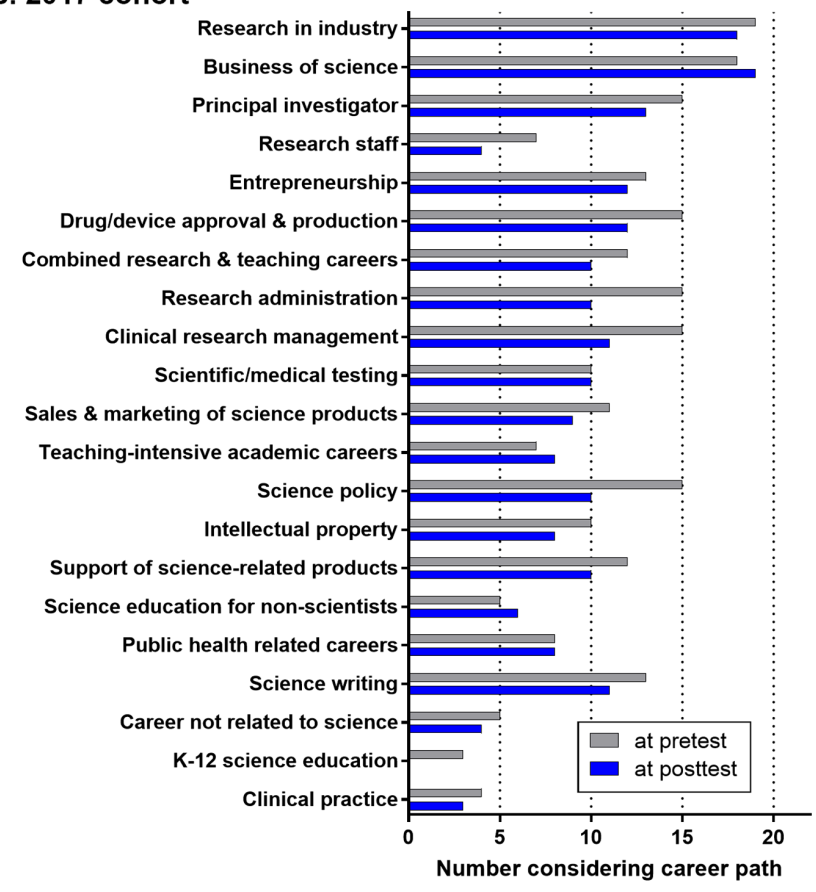

FIGURE 3. Career interests of module participants on the first and last day of class. (A) 2016 cohort $(n=22)$ and (B) 2017 cohort $(n=19)$. Participants indicated the extent to which they were considering 21 different career areas using a Likert scale. An answer was required for each career area, and answer options were: will definitely pursue, strongly considering, moderately considering, slightly/not at all considering, and not familiar enough to decide. For analysis, the five answer options were collapsed into two categories: "considering" (which encompassed will definitely pursue, strongly considering, and moderately considering) and "not considering" (which encompassed slightly/not at all considering and not familiar enough

\section{Rate the following statements as they pertain to your career}

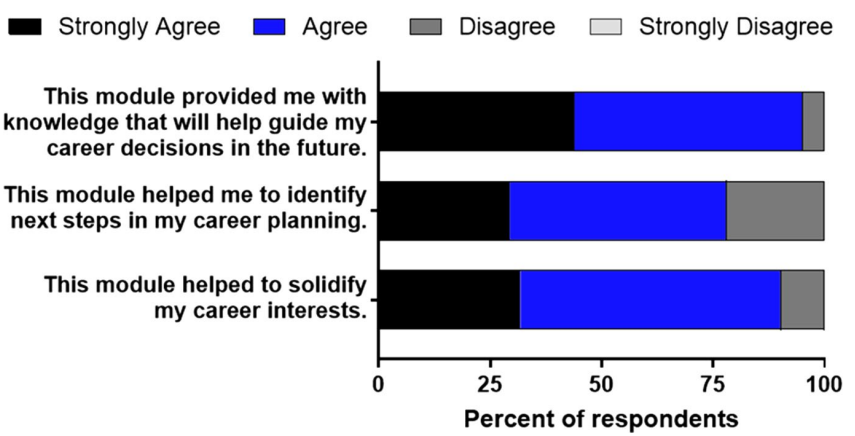

FIGURE 4. Trainee perceptions of the impact of the module on their career interests and career decision making. Participants in the 2016 and 2017 cohorts were asked to rate three statements relating to the impact of the module on their careers using a four-point Likert scale (strongly agree, agree, disagree, strongly disagree). $n=41$.

discoveries (Benderly, 2005; Burroughs Wellcome Fund and Howard Hughes Medical Institute, 2006; Fiske, 2012; Pain, 2014; Tachibana, 2016; Denecke et al., 2017).

Participants in our program were exposed theoretically and practically to business fundamentals. The scores of both the 2016 and 2017 cohorts on a multiple-choice test improved significantly after completing the 12-week didactic module and project. The multiple-choice test questions were identical on the pre- and posttest and aligned with the module learning objectives, suggesting that this efficient approach does improve trainees' understanding of business concepts. It is possible that trainees performed better on the posttest simply by taking the pretest. Such "testing threats" to internal validity can occur if participants remember the pretest questions or learn the material simply by taking the pretest (Campbell and Stanley, 1963; Cor, 2016). Although we cannot rule this out, familiarity with the test seems unlikely to account for the magnitude of the improvement, which was remarkably similar for both cohorts (17.7 percentage points for 2016 and 17.8 percentage points for 2017). Additionally, no answer key was shared with trainees between the pre- and posttest, the pre- and posttest were administered 10 weeks apart, and trainees were not notified of their test scores at any point.

According to a recent report from the CGS, employers deem professional skills like teamwork, communication, and project management as essential to job success but often underdeveloped in STEM PhD graduates (Denecke et al., 2017). Employers interviewed for the CGS report suggested that $\mathrm{PhD}$ students would ideally develop such skills through integrative and experiential learning opportunities that occur contextually. Consistent with this recommendation, a key element of this module was the project, which required teams of trainees to develop a solution to a business challenge faced by a Vanderbilt University core facility and present the solution to a panel of research

to decide). A McNemar test was used to detect a change in individuals' career interests between the first and last days of class. Figures show the numbers of individuals considering a particular career path at the time the pretest (gray) or posttest (blue) was administered. ${ }^{*}, p<0.05 ;^{\ddagger}, p=0.074$. 


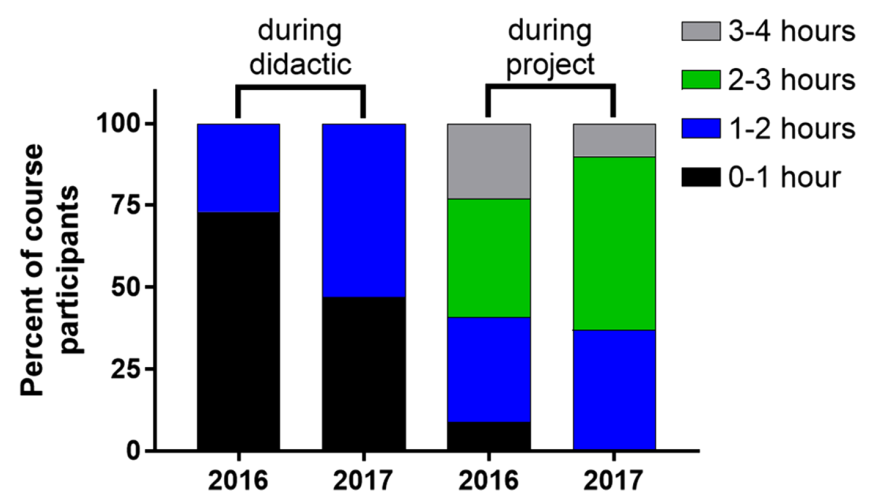

FIGURE 5. Time spent on course-related work by participants in the 2016 and the 2017 cohorts during the didactic and project portions of the class. $n=41$.

administrators, faculty, and business experts. The projects gave trainees the chance to apply their newfound business knowledge in a scientific research context, and more than $90 \%$ of module participants agreed or strongly agreed that the projects helped drive home the concepts taught in class. Furthermore, working in teams on a time-sensitive project and creating a 7-minute "pitch" presentation about their solution gave trainees the opportunity to develop teamwork, project management, and communication skills.

Despite concerted efforts by funding agencies and institutions to expand training opportunities and embrace diverse career outcomes (National Institute of General Medical Sciences, 2011; NIH, 2012; Mathur et al., 2015; Meyers et al., 2015), some graduate students and postdoctoral fellows perceive their research advisors to be unsupportive of trainees who pursue nonfaculty careers (Sauermann and Roach, 2012; Gibbs et al., 2015; Fuhrmann, 2016; Denecke et al., 2017). Fortunately, the majority of trainees in this program perceived their research advisors as supportive or neutral about their participation.

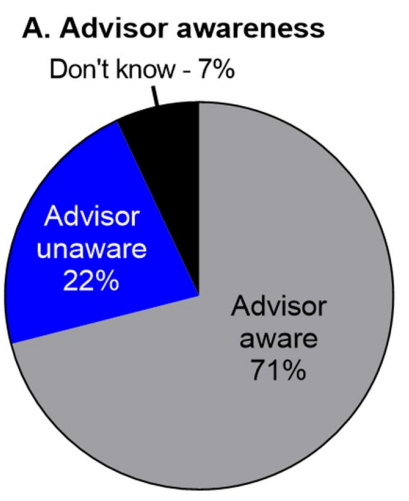

\section{B. Advisor support}

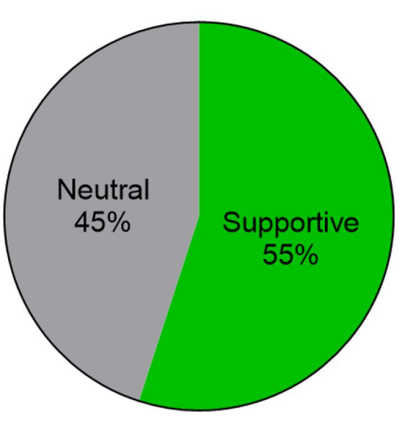

FIGURE 6. Advisor awareness of (A) and support for (B) trainee participation in the module. On the postmodule survey, participants in the 2016 and 2017 cohorts were asked to indicate whether their advisor was aware of their participation in the module. Of 43 survey respondents, 41 answered this question. Those who said their advisors were aware were subsequently asked whether their advisors were supportive, neutral, or not supportive of their participation. $\boldsymbol{n}=\mathbf{2 9}$.
Advisors may have been supportive because this module did not require significant time commitment and it covered fundamental management and business concepts relevant to a range of careers, including careers as PIs. It is also possible that trainees self-selected during the application process, and students and postdocs did not bother to apply if they expected their research advisors to be unsupportive. We cannot draw conclusions based on this limited experience with 44 trainees, but we are encouraged nonetheless that most participants were forthright with their advisors and their advisors were neutral or encouraging.

While it would be ideal to query research advisors directly for their opinions, we did not survey faculty because trainee participants were encouraged but not required to discuss the module with their advisors. Faculty permission was not required because the time commitment was small and federal agencies recognize professional development as an essential part of training rather than as detracting from research (Bernstein, 2014). Furthermore, we feel that requiring trainees to seek permission to participate in relatively low-intensity career development activities ultimately diminishes trainee autonomy.

A major goal of this module was to aid trainees in their career development. Greater than $90 \%$ of participants strongly agreed or agreed that the module helped solidify their career interests and provided them with knowledge that will help guide their career decisions in the future. For the 2016 cohort, trainee interest in most career areas was unchanged between the beginning and end of the module, except for an increase in interest in careers relating to support of science-related products and business of science, although the latter increase was not statistically significant. From the outset of the module, the 2017 cohort was more interested in careers relating to business of science compared with the 2016 cohort, and those interests did not shift during the module.

Some faculty PIs have expressed concern that by providing career and professional development training that pertains to nonacademic careers, we implicitly devalue the research-intensive academic career path or discourage trainees from pursuing such a career (K.P. and K.G., personal discussions). Notably, this module did not cause a significant shift in interest away from the PI career path. Because the module emphasized fundamental business concepts and project-based learning rather than specific career paths, we hypothesize that the module influenced career development primarily by changing trainees' self-efficacy pertaining to business-related competencies (Lent, 2005). Consistent with this interpretation, in the qualitative assessment of module concepts, participants in both the 2016 and 2017 cohorts reported being more comfortable with the six major topic areas after the module.

Together, our quantitative and qualitative metrics show that this novel, efficient approach to providing business training benefits trainee career development. At the same time, it seems likely to have benefited the institutional research mission by improving core operations and fostering long-term collaboration among core directors. This novel mechanism for improving core operations could serve as a model for other institutions as well, as many core directors meet through the Association of Biomolecular Resource Facilities to share best practices and operational strategies. In sum, this program has achieved several goals, and we plan to continue offering it annually for research trainees and core facility managers. 


\section{ACKNOWLEDGMENTS}

We are grateful to the Burroughs-Wellcome Fund for supporting the development and implementation of this module. In addition, we thank Liane Moneta-Koehler for statistical consultation.

\section{REFERENCES}

Benderly, B. L. (2005). Hughes, Burroughs-Wellcome course launches initiative in career-skills education. Science, Retrieved April 28, 2017, from www.sciencemag.org/careers/2005/07/hughes-burroughs-wellcome -course-launches-initiative-career-skills-education

Bernstein, R. (2014). Yes, you can attend that career event, says the U.S. government. Science. Retrieved June 16, 2017, from www.sciencemag .org/careers/2014/12/yes-you-can-attend-career-event-says-us -government

Burroughs Wellcome Fund and Howard Hughes Medical Institute. (2006) Making the right moves: A practical guide to scientific management for post docs and new faculty. Retrieved April 28, 2017, from http://doi.org/10.1016/ j.virol.2008.10.026

Campbell, D. T., \& Stanley, J. C. (1963). Experimental and quasi-experimental designs for research. Boston, MA: Houghton Mifflin Company.

Cor, M. K. (2016). Trust me, it is valid: Research validity in pharmacy education research. Currents in Pharmacy Teaching and Learning, 8(3), 391400. http://doi.org/10.1016/j.cptl.2016.02.014

Denecke, D., Feaster, K., \& Stone, K. (2017). Professional development: Shaping effective programs for STEM graduate students. Washington, DC: Council of Graduate Schools. Retrieved April 28, 2017, from http://cgsnet .org/ckfinder/userfiles/files/CGS_ProfDev_STEMGrads16_web.pdf

Fiske, P. S. (2012). Enterprising science. Nature, 485(7397), 269-270. http:// doi.org/10.1038/nj7397-269a.

Fiske, P. S. (2016). A bridge to business. Nature, 530, 243-245. http://doi .org/10.1038/nj7589-243a.

Freedman, T. (2009). Career opportunities in biotechnology and drug development, Cold Spring Harbor, NY: Cold Spring Harbor Press.

Fuhrmann, C. (2016). Enhancing graduate and postdoctoral education to create a sustainable biomedical workforce. Human Gene Therapy, 27(11) 871-879. http://doi.org/10.1089/hum.2016.154

Fuhrmann, C., Hobin, J., Lindstaedt, B., \& Clifford, P. (2012). MyIDP Science Careers. Retrieved February 25, 2017, from http://myidp.sciencecareers.org

Garrison, H. (2017). Education and Employment of Biological and Medical Scientists 2016: Data from National Surveys. Retrieved January 4, 2017, from http://faseb.org/Resources-for-the-Public/News-Room/Article-Detail
-View/tabid/1014/Articleld/1442/FASEB-Releases-Updated-Resources -and-Analyses-Science-Funding-and-Employment.aspx

Gibbs, K. D., McGready, J., \& Griffin, K. (2015). Career development among American biomedical postdocs. CBE-Life Sciences Education, 14(4), ar44. http://doi.org/10.1187/cbe.15-03-0075

Janssen, K., \& Sever, R. (2014). Career options for biomedical scientists. Cold Spring Harbor, NY: Cold Spring Harbor Press.

Lent, R. W. (2005). A social cognitive view of career development and counseling. In Career development and counseling: Putting theory and research to work (pp. 101-127). Hoboken, NJ: John Wiley \& Sons.

Mason, J. L., Johnston, E., Berndt, S., Segal, K., Lei, M., \& Wiest, J. S. (2016) Labor and skills gap analysis of the biomedical research workforce. FASEB Journal, 30(8), 2673-2683. http://doi.org/10.1096/fj.201500067R

Mathur, A., Meyers, F. J., Chalkley, R., O'Brien, T. C., \& Fuhrmann, C. (2015). Transforming training to reflect the workforce. Science Translational Medicine, 7(285). http://doi.org/10.1126/scitranslmed.aaa8200

Meyers, F., Mathur, A., Fuhrmann, C., O'Brien, T. C., Wefes, I., Labosky, P. A. ... Chalkley, R. (2015). The origin and implementation of the Broadening Experiences in Scientific Training programs: An NIH common fund initiative. FASEB Journal, 30(2), 1-8. http://doi.org/10.1096/fj.15 $-276139$

National Institute of General Medical Sciences. (2011). Investing in the Future: Strategic Plan for Biomedical and Behavioral Research Training. Retrieved April 28, 2017, from http://publications.nigms.nih.gov/trainingstrategicplan

National Institutes of Health. (2012). Biomedical Research Workforce Working Group report, Bethesda, MD. Retrieved April 28, 2017, from http:// acd.od.nih.gov/Biomedical_research_wgreport.pdf

Pain, E. (2014). Innovative training for biomedical technology. Science. Retrieved April 28, 2017, from www.sciencemag.org/careers/2014/05/ innovative-training-biomedical-technology

Sauermann, H., \& Roach, M. (2012). Science PhD career preferences: Levels, changes, and advisor encouragement. PLoS One, 7(5), e36307.

Sinche, M. (2016). Next gen PhD: A guide to career paths in science. Cambridge, MA: Harvard University Press.

Stephan, P. (2012). How economics shapes science. Cambridge, MA: Harvard University Press.

Tachibana, C. (2016). Business principles for basic researchers. Science. Retrieved April 1, 2017, from www.sciencemag.org/careers/features/2016/ 10/business-principles-basic-researchers

Turpen, P. B., Hockberger, P. E., Meyn, S. M., Nicklin, C., Tabarini, D., \& Auger J. A. (2016). Metrics for success: Strategies for enabling core facility performance and assessing outcomes. Journal of Biomolecular Techniques, 27(1), 25-39. http://doi.org/10.7171/jbt.16-2701-001 